\title{
Lightweight Software Architecture Evaluation for Industry: A Comprehensive Review
}

\author{
Mahdi Sahlabadi (D, Ravie Chandren Muniyandi (D), Zarina Shukur and Faizan Qamar *(D) \\ Centre for Cyber Security, Faculty of Information Science and Technology (FTSM), \\ Universiti Kebangsaan Malaysia (UKM), Bangi 43600, Selangor, Malaysia; sahlabadi2002@gmail.com (M.S.); \\ ravie@ukm.edu.my (R.C.M.); zarinashukur@ukm.edu.my (Z.S.) \\ * Correspondence: faizanqamar@ukm.edu.my
}

Citation: Sahlabadi, M.; Muniyandi, R.C.; Shukur, Z.; Qamar, F. Lightweight Software Architecture Evaluation for Industry: A

Comprehensive Review. Sensors 2022, 22, 1252. https://doi.org/10.3390/ s22031252

Academic Editor: Francesco Mercaldo

Received: 2 December 2021 Accepted: 27 January 2022 Published: 7 February 2022

Publisher's Note: MDPI stays neutral with regard to jurisdictional claims in published maps and institutional affiliations.

Copyright: (c) 2022 by the authors. Licensee MDPI, Basel, Switzerland. This article is an open access article distributed under the terms and conditions of the Creative Commons Attribution (CC BY) license (https:// creativecommons.org/licenses/by/ $4.0 /)$.

\begin{abstract}
Processes for evaluating software architecture (SA) help to investigate problems and potential risks in SA. It is derived from many studies that proposed a plethora of systematic SA evaluation methods, while industrial practitioners currently refrain from applying them since they are heavyweight. Nowadays, heterogeneous software architectures are organized based on the new infrastructure. Hardware and associated software allow different systems, such as embedded, sensorbased, modern AI, and cloud-based systems, to cooperate efficiently. It brings more complexities to SA evaluation. Alternatively, lightweight architectural evaluation methods have been proposed to satisfy the practitioner's concerns, but practitioners still do not adopt these methods. This study employs a systematic literature review with a text analysis of SA's definitions to propose a comparison framework for SA. It identifies lightweight features and factors to improve the architectural evaluation methods among industrial practitioners. The features are determined based on the practitioner's concerns by analyzing the architecture's definitions from stakeholders and reviewing architectural evaluation methods. The lightweight factors are acquired by studying the five most commonly used lightweight methods and the Architecture-based Tradeoff Analysis Method (ATAM), the most well-known heavyweight method. Subsequently, the research addresses these features and factors.
\end{abstract}

Keywords: software architectural evaluation; lightweight software architecture; heavyweight software architecture; software quality

\section{Introduction}

It is essential to detect software architecture (SA) problems before software development, but it is not easy to analyze SA because of software heterogeneity and the arrangement of software components [1,2]. Consequently, the problematic SA leads to project failure; therefore, different big, upfront designs are sketched based on the experiences of software analysts to explore the SA problems in the early phase [3]. Modern SA works based on various Flask web servers and local Raspberry servers, connected via cloud technology to a central platform. They receive user requests and control the protocol through a REST API to command microcontrollers and detect sensor faults. Internet of Things (IoT) devices with resource limitations are programmed with high-complex languages, such as Python, $\mathrm{C}++$, and even Java, which significantly differ from the traditional monolithic SA. It is very difficult to analyze the intercommunication of all those elements $[4,5]$.

A successful software project delivers the agreed-upon functionalities in the software within the triangle of a specific time, budget, and acceptable quality [6]. An SA plays a vital role in this triangle since the SA initializes system design with models and analysis to ensure that the design meets the system's functional and non-functional requirements. It extends and sustains the system by integrating it with other systems. Changes to the existing requirements always happen and may change the SA, bringing massive code rework and impacting the schedule and budget [7]. 
In recent years, many researchers have proposed different SA evaluation methods to uncover SA problems systematically. Generally, SA evaluations are beneficial and economical to detect the early stage's risks or issues, but they are heavyweight and costly to maintain [8]. Despite the crucial role of architectural evaluation and many SA evaluation methods proposed by research communities, the industry only occasionally practices these methods [9]. Researchers proposed various SA evaluation methods based on different techniques such as scenario, simulation, etc. For example, the most popular scenario-based methods are different versions of the ATAM, the Software Architecture Analysis Method (SAAM), and Performance Assessment of Software Architecture (PASA). These methods, which are expensive and time-consuming, might be applied in the different software development stages. Moreover, the practitioners do not acquire business values for these assessments, while several stakeholders must participate in the SA's documentation [10]. They are inefficient in coping with this complex technical topic since they rely on limited scenarios [11-13]. As a result, other approaches such as simulation and mathematics were used to promote the methods; however, the architectural evaluation methods are still heavyweight [14].

These limitations have triggered another wave of research for lightweight SA evaluation methods such as lightweight ATAM, Pattern-Based Architecture Reviews (PBAR), and Active Reviews for Intermediate Designs (ARID). It also helps to reduce the cost of the assessment process, time, and effort by minimizing the SA documentation, formality, and involved stakeholders. Although researchers took a step towards practitioners' needs, similar to the non-lightweight methods, the lightweight methods are not being used widely in the industry $[15,16]$.

The persistence of not using SA evaluation methods brings up the following research questions: Q1: What features and influencing factors encourage the industry to use lightweight SA evaluations? This exploratory research aims to identify the features and characteristics that enable lightweight SA evaluations in the industry. Q2: What are the differences between the aspects of SA's from industry and academic backgrounds? This study extracts differences between the following two major SA communities: practitioners and researchers, through the comparative text analysis of SA definitions and the systematic literature review of existing methods.

Every SA evaluation method consists of the following three main parts: SA design and presentation concepts, SA evaluation procedures, and quality attributes (QA) of SA. This research is aligned to identify features and factors for a solution based on them. Besides, considering that SA is deeply concerned with industrial needs, this research makes an effort to find industrial views of SA to guide the researchers. The history of the SA standards, concepts, and definitions is discussed in the first two sections. The SA design methods section reviews and discusses the most commonly used SA design processes, styles, and presentations. In the SA evaluation section, all the SA evaluation methods are briefly reviewed and examined to identify criteria for comparing SA evaluation methods. Then, comprehensively, the most commonly used lightweight approaches are discussed to identify their strengths and weaknesses. Ultimately, this comprehensive comparison determines the lightweight factors of the SA evaluation methods. Then, there are discussions about the most concerning targeted QAs. In the end, the research discusses the identified features and factors and their relationships. Then, the next section discusses the achievements and results. Lastly, the conclusion section wraps up all the discussion. Research generally offers an added value to SA evaluation by the evaluation approach's overview. It contrasts the benefits and drawbacks of proposed approaches and presents their constraints. Furthermore, the approaches are closely interrelated and similar. As a result, it is significant to compare existing approaches to help software architects select the most viable option from a set of approaches. 


\section{Software Architecture Definition Differences}

Although SA has been used for decades, professionals still cannot refer to a single SA definition as stakeholders recognize "architecture" based on their interests [17-20]. Therefore, it leads to different purposes for SA, where standards derive between common vocabularies and understanding. The standard IEEE 1471, and its refined successor version ISO/IEC/IEEE 42010: 2011, tried to address stakeholders' concerns, but researchers and specialists did not give major attention to these standards as they were general [21]. The SA standards are naturally genuine standards following a "late adaption," as they emerged because of awareness of their usage. They are also an "open standard" that permits more people to get involved in the standard's definition.

Moreover, this standard may apply the same methods to a wide range of conditions, so the stakeholders avoid SA standards [22]. As SA standards are a type of late adaption and SA was established in the industry, academics follow it. Therefore, to challenge this academic research, when the new SA trends originating from the industry are recognized, this academic research can be associated with these trends. Therefore, the parties to the standards are the academic and practitioner architect communities. This research seeks the differences between academic and industry definitions of SA by applying the textanalyzing technique to a web definition repository by using data mining, which identifies new SA trends.

The Software Engineering Institute of Carnegie Mellon University provides comprehensive online repositories of SA definitions [23]. Retrieved data of community SA definitions are compared with classical, bibliographical, and modern SA descriptions. These definitions are divided into the following two groups: First, community SA, which collects practitioners' definitions, and second, academic and conventional definitions. First, the keywords from the two groups of definitions are extracted, and then the buzzwords are omitted. Second, the words are rooted, and some terms that refer to the same concept are considered one word concerning the three elements of SA definitions (component, connector, and constraint) [24]. For instance, (connector, glue), (component, service, element, unit, module), (constraint, limitation), etc. In the end, 127 words are recognized for each group, and the words are ranked based on their occurrences. The most frequent keyword between communities is "design". Differences between the existing definitions illustrate the real need for SA, which practical stakeholders have perceived. The result indicates "Time", "Cost", "Complexity", and 'Distributed' are widespread words that belong to community SA definitions that are not in academic definitions of keyword lists.

Meanwhile, for the academic group's sake, this study refers to Muccini et al. [25], which conducted a systematic review by data mining techniques on the selected topics in SA, containing 811 published studies from 1999 to 2016. The result indicates most of the studies are concerned about "performance and security analysis". Moreover, there are new rising trends in SA's agility that are mostly distributed and heterogeneous systems, which have been investigated as an application area due to their complexity.

The default antonym of "Time", "Cost", and "Complexity" means lightweight, which is fast, cheap, and straightforward [26]. "Distributed" systems are "heterogeneous" and intricate systems that derive from complex SA [27]. It means that "Complexity" increases the "Cost" and "Time" of the SA design and evaluation. Therefore, this research implies that SA communities need a lightweight SA evaluation framework, which analyzes distributed and the performance and security of heterogeneous systems.

It refers to overall performance and security, two qualities concerned with the system execution. Security may vary radically from one case to another, but performance is broadly the system's responsiveness and time of interaction between software components. These qualities are discussed in more detail in Sections 5.1 and 5.2.

\section{Software Architecture Design}

The lack of standards in SA presentations may cause a mismatch between the SA presented and the actual SA. The Unified Modeling Language (UML) has become an 
international standard, ISO/IEC 19505: 2012, and has been accepted as an effective industrial standard for SA [28]. However, UML notation meets the user's needs and is flexible enough to follow their expectations; this flexibility is embedded in semantic informality that can be understood differently [29,30]. Some researchers [27-33] imply that UML per se is not enough, and there is a need for a formal approach to adapt the UML. Moreover, Rodriguez et al. [31] and Medvidovic et al. [32] proved Petri net supremacy over architectural description languages (ADLs) and formal methods languages. As a result, Petri net can bridge this gap. Additionally, Jensen et al. [33] and Emadi et al. [34] stated that timed hierarchical colored Petri net is a compatible version of Petri net that can be utilized to simulate complex data values and SAs [35].

Architectural patterns are an ideal complement to architectural decisions. An architectural design, interchangeably called architectural style, is specified as a set of principles besides a coarse-grained pattern abstract framework for systems [36,37]. It is a standard solution, reused and partitioned for chronic issues in the SA area. An architectural style thoroughly regulates the vocabulary of components and connectors. It means how they can be together with a set of constraints. It may impose some topologic restraints on architectural explanations [38].

Additionally, it may have some execution semantics, which can be part of the style definition $[39,40]$. For the rising concern of distributed and heterogeneous software mentioned in the previous section, the commonly used architectural styles are client/server, component-based architecture, domain-driven design, layered architecture, message bus, $\mathrm{N}$-tier/3-tier, object-oriented, SOA, and pipe and filter. In practice, the standard SA of a system is mainly made up of a pattern of different architectural styles for systems [41].

Despite the popularity of domain-driven design, layered architecture, message bus, $\mathrm{N}$-tier/3-tier, and object-oriented modeling, it is challenging to scale them up. Moreover, there is no tool to analyze or measure non-functional properties. The interconnection mechanisms are so basic (method invocation); thus, complex interconnections are so hard in these methods. In a nutshell, there is no clear image of system architecture before component creation [42]. Component-based SA relieves this modeling trouble and develops reusable off-the-shelf component-based heterogeneous systems.

In comparison with other SA styles, a component or connector has a higher level of roughness. ISO/IEC/IEEE 42010: 2011 defines this architectural type as an effective standard [43]. Along with component-based architecture, SOA, and pipe and filter facilitate the handling of non-functional properties. It has the excellent capability of making complex products, apart from what kind of platform or technology is used in these products. However, in comparison, the presentation is still a problem in both styles [44-47].

\section{Software Architecture Evaluation}

This section examines the existing literature on SA evaluation for the last three decades to answer research questions about SA evaluation [48]. This systematic review results in the factors that can be used for proposing an evaluation framework.

After more than 30 years of SA evaluations, many research questions remain open about the categorization of SA evaluations. This section determines the criteria for the classification of SA evaluations to identify factors for SA evaluation. In this study, for the systematic review of the literature, the terms of SA "Review", "Evaluation", "Analysis", "Assessment", and "Validation" are used interchangeably as search keywords.

Figure 1 and Table 1 indicate that 27 credential SA evaluations have been selected to review from IEEE, Springer, ACM, Elsevier, and Google Scholar. They are the standard methods and techniques of SA evaluation. 
Table 1. The selected published papers in SA evaluation.

\begin{tabular}{|c|c|}
\hline Reference Study & Focus \\
\hline Breivold et al. [49] & $\begin{array}{l}\text { The search identified } 58 \text { studies that were cataloged as primary studies for this review after using a multi-step selection process. The studies are } \\
\text { classified into the following five main categories: techniques supporting quality considerations during SA design, architectural quality evaluation, } \\
\text { economic valuation, architectural knowledge management, and modeling techniques. }\end{array}$ \\
\hline Barcelos et al. [50] & A total of 11 evaluation methods based on measuring techniques are used, mainly focusing on simulation and metrics to analyze the architecture. \\
\hline Suman et al. [51] & This paper presents a comparative analysis of eight scenario-based SA evaluation methods using a taxonomy. \\
\hline Shanmugapriya et al. [52] & It compares 14 scenario-based evaluation methods and five of the latest SA evaluation methods. \\
\hline Roy et al. [53] & $\begin{array}{l}\text { The taxonomy is used to distinguish architectural evaluations based on the artifacts on which the methods are applied and two phases of the software } \\
\text { life cycle. }\end{array}$ \\
\hline Mattsson et al. [54] & The paper compares 11 various evaluation methods from technical, quality attributes, and usage views. \\
\hline Hansen et al. [55] & $\begin{array}{l}\text { The research reports three studies of architectural prototyping in practice, ethnographic research, and a focus group on architectural prototyping. It } \\
\text { involves architects from four companies and a survey study of } 20 \text { practicing software architects and developers. }\end{array}$ \\
\hline Gorton et al. [56] & $\begin{array}{l}\text { This paper compares four well-known scenario-based SA evaluation methods. It uses an evaluation framework that considers each method for context, } \\
\text { stakeholders, structure, and reliability. }\end{array}$ \\
\hline Weiss et al. [57] & $\begin{array}{l}\text { It conducted a survey based on architectural experience, which was organized into six categories. The architecture reviews found more than } 1000 \text { issues } \\
\text { between the years } 1989 \text { and } 2000 .\end{array}$ \\
\hline Suryanarayana et al. [59] & It states refractory adaption for architecture evaluation methods. \\
\hline Lindvall et al. [60]; Santos et al. [61] & These are references of reviewed papers lacking stated knowledge, which is needed in the paper or more investigation. \\
\hline Oliveira et al. [62] & It reviews the agile SA evaluation. \\
\hline Martensson et al. [63] & It reviews the scenario-based SA evaluation based on industrial cases. \\
\hline
\end{tabular}




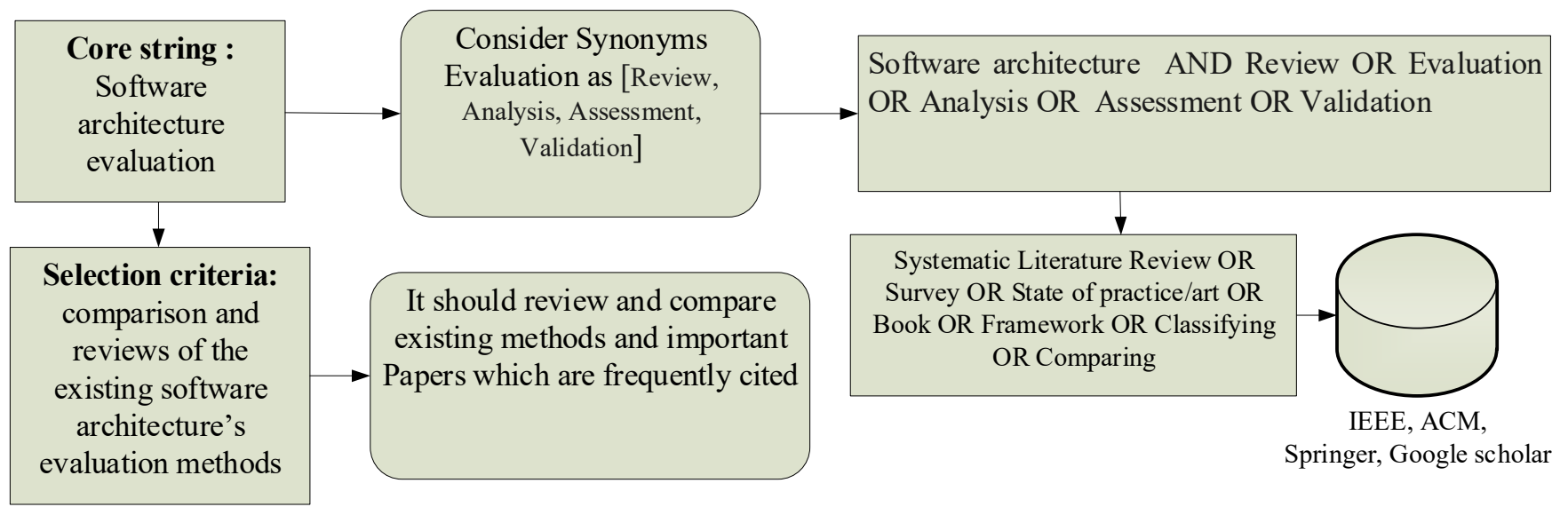

Figure 1. The strategy for selecting credential research and SA evaluation methods.

Although SA evaluation is an important activity at any stage of the software life cycle, it is not widely practiced in the industry [64]. Gorton et al. [65] conducted largescale research to identify the industrial practices of architecture evaluations to categorize SA evaluations based on evaluation techniques. Table 2 indicates the investigations in architectural evaluations from the industrial aspect. The techniques and methods listed in the first column of Table 2 are based on the frequency of use in industry; these techniques are used in the evaluation methods. The most frequent methods of each technique are listed below, and the quality attributes (QAs) are applied to them. These methods are elicited from systematic literature reviews and the latest related academic papers and books.

Despite the encouraging number of basic research found (76 approaches), it is evident that only 27-SA evaluation approaches, regardless of their targeted QAs. This table tries to compare the techniques of approaches. Later on, in Section 5, the target quality attributes will be discussed. There are some reasons for such a massive decrease in the amount of research. First, there were some identical entries for the same article when we searched in numerous databases. Second, a large percentage of the study evaluated one or several QAs in a subtle ad hoc way. Consequently, those studies are omitted, as they did not manuscript a repeatable evaluation process or method. Third, some studies considered both software and hardware evaluations, so they were not suitable in the current research emphasizing SA evaluation approaches. Below, the techniques and methods are discussed.

- The first technique focuses on experience, where SA plays a vital role in design and evaluation [66]. This is the most practiced technique by the industrial section [56]. Empirically Based Architecture Evaluation (EBAE) is performed late in development. At the same time, Attribute-Based Architectural Styles (ABAS) can run during the design time and get integrated with ATAM [49,60,67]. Decision-Centric Architecture Reviews (DCAR) analyse a set of architectural decisions to identify if the decision taken is valid. It is more suitable for agile projects due to its lightweight [62].

- The second-most popular technique is the prototype that collects early feedback from the stakeholders based on and enables architecture analysis to look at close-to-real conditions. It may answer questions that cannot be resolved by other approaches [68].

- The third technique is a scenario-based evaluation. SAAM is the earliest method using scenarios and multiple SA candidates. Later on, ATAM completed SAAM by trade-off analysis between QAs, where ATAM uses qualitative and quantitative techniques. The Architecture-Level Modifiability Analysis (ALMA) and Performance Assessment of Software Architecture (PASA) have been used to combine scenarios and quantitative methods to boost the results $[69,70]$.

- The fourth technique is checklists, consisting of detailed questions assessing the various requirements of architecture. Software Review Architecture (SAR) uses checklists according to the stakeholder's criteria and the system's characteristics. The Framework of Evaluation of Reference Architectures (FERA) exploits the opinions of experts in 
SA and reference architectures. There is a need for a precise understanding of the requirements to create the checklist [71,72].

- The fifth technique is simulation-based methods, which are very tool-dependent; the Architecture Recovery, Change, and Decay Evaluator/Reference Architecture Representation Environment (ARCADE/RARE) simulates and evaluates architecture by automatic simulation and interpretation of SA [73]. An architecture description is created using the subset of toolset called Software Engineering Process Activities (SEPA), descriptions of usage scenarios are input to the ARCADE tool [74]. Many tools and toolkits transform architecture into layered queuing networks (LQN) [75]. It requires special knowledge about the component's interaction and behavioral information, execution times, and resource requirements [76]. Formal Systematic Software Architecture Specification and Analysis Methodology (SAM) follows formal methods and supports an executable SA specification using time Petri nets and temporal logic [77]. It facilitates scalable SA specification by hierarchical architectural decomposition.

- The sixth category is for metrics-based techniques that need to be mixed with other techniques, and they are not intrinsically powerful enough [78]. Here are some examples of metric-based methods. The Software Architecture Evaluation on Model (SAEM) is based on the Goal/Question/Metric Paradigm (GQM) to organize the metrics. Metrics of Software Architecture Changes based on Structural Metrics (SACMM) measures the distances between SAs endpoints by graph kernel functions [79]. Lindvall et al. [60] introduced late SA metrics-based approaches to compare the actual SA with the planned architecture.

- The seventh technique, focusing on mathematical-model-based methods, is highlighted in the research areas, but the industry does not attend to them. Software Performance Engineering (SPE) and path and state-based methods are used to increase the reliability performance. These modeling methods exploit mathematical equations resulting in architectural statistics such as the mean execution time of a component and can be mixed with simulation $[80,81]$.

Concisely, all the above discussion derives is that scenarios-based evaluation techniques are well-investigated and broadly reviewed in research papers. It has been completed by other techniques, such as simulations and mathematical techniques, to perform effectively. Another technique is simulation, focusing on the main components of a planned or implemented architecture to simulate context. While mathematical techniques use static evaluation of architectural designs, some modeling techniques originate from highperformance computing and real-time systems. Experienced-based techniques are different from other techniques. They are less explicit, and they are based on subjective factors, namely, intuition and experience. This technique is based on reviewer perception, objective argumentation, and logical reasoning. For example, an expert might recognize an availability problem, and then they convince others through scenarios that depict the situation. 
Table 2. SA evaluation categorization

\begin{tabular}{|c|c|c|c|}
\hline Techniques & Methods & Quality Attribute & Remarks \\
\hline \multirow{3}{*}{$\begin{array}{l}\text { Experience-based } \\
\text { Experts encountered the software system's requirements } \\
\text { and domain. }\end{array}$} & EBAE (Empirically Based Architecture Evaluation) & Maintainability & \multirow{3}{*}{$\begin{array}{l}\text { The most common technique applied to review } \\
\text { architecture in the industry [5], based on } \\
\text { expert's knowledge and documents. }\end{array}$} \\
\hline & ABAS (Attribute-Based Architectural Styles) & Specific QAs & \\
\hline & DCAR (Decision-Centric Architecture Reviews) & All & \\
\hline $\begin{array}{l}\text { Prototyping-based } \\
\text { Incrementally prototyping before developing a product to } \\
\text { get to know the problem better. }\end{array}$ & Exploratory, Experimental, and Evolutionary & Performance and modifiability & $\begin{array}{l}\text { The delighted techniques have been applied to } \\
\text { review industry architecture; possibly an } \\
\text { evolutionary prototype can be developed into a } \\
\text { final product. }\end{array}$ \\
\hline \multirow{7}{*}{$\begin{array}{l}\text { Scenario-based } \\
\text { The specific quality attribute is evaluated by creating a } \\
\text { scenario profile conducting a concrete description of the } \\
\text { quality requirement. }\end{array}$} & SAAM (Software Architecture Analysis Method) & \multirow{5}{*}{ All } & \multirow{7}{*}{$\begin{array}{l}\text { Scenario is a short description of stakeholders' } \\
\text { interaction with a system. Scenario-based } \\
\text { methods are widely used and well known [49]. }\end{array}$} \\
\hline & ATAM (Architecture Trade-off Analysis Method) & & \\
\hline & Lightweight-ATAM (derived from ATAM) & & \\
\hline & ARID (Active Reviews for Intermediate Designs) & & \\
\hline & PBAR (Pattern-Based Architecture Reviews) & & \\
\hline & ALMA (Architecture Level Modifiability Analysis) & Modifiability & \\
\hline & PASA (Performance Assessment of Software Architecture) & Performance & \\
\hline $\begin{array}{l}\text { Checklist-based } \\
\text { A checklist includes a list of detailed questions to evaluate } \\
\text { an architecture. }\end{array}$ & Software Review Architecture (SAR) & All & $\begin{array}{l}\text { It depends on the domain, meaning that a new } \\
\text { checklist must be created for each } \\
\text { new evaluation. }\end{array}$ \\
\hline \multirow{3}{*}{$\begin{array}{l}\text { Simulation-based } \\
\text { It provides answers to specific questions, such as the } \\
\text { system's behavior under load. }\end{array}$} & $\begin{array}{l}\text { ARCADE/RARE (Architecture Recovery, Change, and Decay } \\
\text { Evaluator/Reference Architecture Representation Environment) }\end{array}$ & \multirow{3}{*}{ Performance } & \multirow{3}{*}{$\begin{array}{l}\text { There is a tendency to mix simulation and } \\
\text { mathematical modeling to extend the } \\
\text { evaluation framework. }\end{array}$} \\
\hline & Layered Queuing Networks) & & \\
\hline & $\begin{array}{l}\text { SAM (Formal Systematic Software Architecture Specification } \\
\text { and Analysis Methodology) }\end{array}$ & & \\
\hline \multirow{4}{*}{$\begin{array}{l}\text { Metrics-based } \\
\text { It uses quality metrics to evaluate architecture and } \\
\text { its representation. }\end{array}$} & $\begin{array}{l}\text { SACMM (Metrics of Software Architecture Changes based on } \\
\text { Structural Metrics) }\end{array}$ & \multirow{2}{*}{ Modifiability } & \multirow{4}{*}{$\begin{array}{l}\text { It is not rampant in the industry. Commonly } \\
\text { other methods exploit metrics to boost } \\
\text { their functionalities. }\end{array}$} \\
\hline & SAEM (Software Architecture Evaluation on Model) & & \\
\hline & Design pattern, conformance with design and violations. & Inter-module coupling violation. & \\
\hline & TARA (Tiny Architectural Review Approach) & Functional and non-functional & \\
\hline $\begin{array}{l}\text { Math Model-based } \\
\text { By mathematical proofs and method, operational qualities } \\
\text { requirements such as performance and reliability are evaluated. }\end{array}$ & $\begin{array}{l}\text { Path and state-based methods } \\
\text { SPE (Software Performance Engineering). }\end{array}$ & $\begin{array}{l}\text { Reliability } \\
\text { Performance }\end{array}$ & $\begin{array}{l}\text { It is mixed with a scenario and } \\
\text { simulation-based architecture to have more } \\
\text { accurate results. }\end{array}$ \\
\hline
\end{tabular}




\subsection{Categorizing of Software Architecture Evaluation}

There is no distinctive categorization in technique-based classifications because hybrid architecture evaluation methods that use multiple architecture evaluation techniques belong to different categories [82]. The selected methods' discussions discover various classifications, comparing them with some commonalities regarding the assessment procedure's activities and artifacts. However, since it is not apparent which methods are the same as the proposed solution, these methods will be analyzed to attain their common aims and an objective mechanism. To address this problem, we have recognized a set of criteria that can provide a foundation for comparing and assessing SA evaluation methods.

This study proposes a comparison framework to present and compare the analysis methods to elaborate on these fundamental criteria. It has been proposed by the combination of three software evaluation comparison frameworks [83,84]. In Table 3, this comparison framework is introduced, which contains the following main components of SA evaluation methods: context, stakeholder, contents, time, and reliability. For each component, the related elements are identified and mentioned. Then the existing taxonomies of these elements are generally mentioned in taxonomic comparison, and the taxonomies are broken down in more detail in the complementary table.

Niemela et al. [85] introduced a framework to compare SA evaluation methods with some essential criteria. These criteria are listed below from $\mathrm{C} 1$ to $\mathrm{C}$, which can be answered concerning Table 3:

C1: The main goal of the method.

C2: The evaluation technique(s).

C3: Covered QAs.

C4: Stakeholder's engagement.

C5: How applied techniques are arranged and are performed to achieve the method goal.

C6: How user experience interferes with the method

C7: Method validation

Other than these criteria, tools, and techniques, and the SA description and outcomes of the methods are also explored. Moreover, C4, C5, and C6 are replied during the review of the SA evaluation "process". These criteria are used to compare the existing solution to identify factors that increase the evaluation framework's use. 
Table 3. Software evaluations comparison framework

\begin{tabular}{|c|c|c|c|}
\hline \multicolumn{4}{|c|}{ Comparison Framework } \\
\hline Component & Elements & Brief Explanation & Taxonomic Comparison \\
\hline \multirow{11}{*}{ Context } & SA definition & Does the method overtly consider a specific definition of SA? & NA \\
\hline & \multirow{2}{*}{ Specific goal } & \multirow{2}{*}{ What is the specific aim of the methods? } & Need for Evolution: Corrective, Perfective, Adaptive, Preventive, All applicable. \\
\hline & & & Means of Evaluation (Dynamic): Reconfiguration, Adaptation \\
\hline & Quality attributes & How many and which QAs are covered by the method? & QAs \\
\hline & Applicable stage & Which is the most suitable development phase for applying the method? & Early \\
\hline & \multirow{2}{*}{ Input and output } & \multirow{2}{*}{ What are the required inputs and produced outputs? } & In: coarse-grained, medium, or fine SA design, views \\
\hline & & & Out: risks, issues \\
\hline & \multirow{3}{*}{ Application domain } & \multirow{3}{*}{ What is/are the application domain(s) the method is often applied? } & Development Paradigm: SPL, OO, SOA, CBS \\
\hline & & & $\begin{array}{l}\text { Traditional: Embedded, Real-time, Process-aware, Distributed, Event-based, Concurrent, } \\
\text { Mechatronic, Mobile, Robotic, Grid computing }\end{array}$ \\
\hline & & & Emerging: Cloud computing, Smart grid, Autonomic computing, Critical system, Ubiquitous \\
\hline & Benefits & What are the advantages of the method to the stakeholders? & NA \\
\hline \multirow{3}{*}{ Stakeholder } & Involved Stakeholders & Which groups of stakeholders are needed to take part in the evaluation? & NA \\
\hline & Socio-technical issues & How does the method handle non-technical (e.g., social, organizational) issues? & $\mathrm{NA}$ \\
\hline & Required resources & How many man-days are needed? What is the size of the evaluation team? & NA \\
\hline \multirow{10}{*}{ Contents } & \multirow{2}{*}{ Method's activities } & \multirow{2}{*}{ What are the activities to be accomplished, and in which order to reach the aims? } & Means of Evolution: Static, Dynamic \\
\hline & & & Support activity: Change impact, Change history \\
\hline & \multirow{4}{*}{ SA description } & \multirow{4}{*}{ What form of SA description is needed (e.g., formal, informal, ADL, views, etc.)? } & Type of Formalism \\
\hline & & & Description of Language \\
\hline & & & UML Specification \\
\hline & & & Description Aspect \\
\hline & Evaluation approaches & What are the types of evaluation approaches applied by the method? & $\begin{array}{l}\text { Experience-based, Prototyping-based, Scenario-based, Checklist-based, Simulation-based, } \\
\text { Metrics-based, Math Model-based }\end{array}$ \\
\hline & \multirow{3}{*}{ Tool support } & \multirow{3}{*}{ Are there tools or experience repositories for supporting the method and its artifacts? } & Need for Tool Support Analysis \\
\hline & & & Usage of Tool Support \\
\hline & & & Level of Automation \\
\hline
\end{tabular}


Table 3. Cont.

\begin{tabular}{|c|c|c|c|}
\hline \multicolumn{4}{|c|}{ Comparison Framework } \\
\hline Component & Elements & Brief Explanation & Taxonomic Comparison \\
\hline \multirow{2}{*}{ Reliability } & Maturity of the method & What is the level of maturity (inception, refinement, development, or dormant)? & $\begin{array}{l}\text { Overview or Survey, Formalism for constraint specification, Formalism for architectural analysis, } \\
\text { Formalism for arch and evolution, Formalism for code generation. }\end{array}$ \\
\hline & Method's validation & Has the method been validated? How has the method been validated? & Case study, Mathematical proof, an Example application, Industrial validation \\
\hline \multirow{3}{*}{ Time } & \multirow{3}{*}{ Time of evaluation } & Stage of evolution & Early, middle, and Post-deployment. \\
\hline & & SLDC & Analysis/Design, Implementation, Integration/provisioning, Deployment, Evolution \\
\hline & & Specification-time & Design-Time, Run-Time \\
\hline \multicolumn{4}{|c|}{ Complementary table } \\
\hline \multicolumn{2}{|c|}{ Means of Evolution: } & \multicolumn{2}{|l|}{ Dynamic: Reconfiguration, Adaptation } \\
\hline \multirow{2}{*}{\multicolumn{2}{|c|}{ Support activity: }} & \multicolumn{2}{|l|}{ Change impact: Consistency checking, Impact analysis, Propagation; } \\
\hline & & \multicolumn{2}{|l|}{ Change history: Evolution analysis, Versioning } \\
\hline \multirow{3}{*}{\multicolumn{2}{|c|}{ Type of Formalism }} & \multicolumn{2}{|c|}{ Modeling language: ADL, Programming languages, Domain-specific language, Type systems, Archface, Model-based } \\
\hline & & \multicolumn{2}{|c|}{ Formal models: Graph theory, Petri-net, Ontology, State machine, Constraint automata, CHAM } \\
\hline & & \multicolumn{2}{|c|}{ Process algebra: FSP, CSP, $\pi$-calculus; Logic (Constraint language): OCL, CCL, FOL, Grammars, Temporal logics, Rules, Description logic, Z, Alloy, Larch } \\
\hline \multicolumn{2}{|c|}{ Description of Language } & \multicolumn{2}{|c|}{ Process algebra: Darwin, Wright, LEDA, PiLar } \\
\hline \multirow{2}{*}{\multicolumn{2}{|c|}{ UML Specification }} & \multicolumn{2}{|c|}{ Static: Class, Component, Object. } \\
\hline & & \multicolumn{2}{|l|}{ Dynamic: Activity, State, Sequence, Transition, Communication } \\
\hline \multicolumn{2}{|c|}{ Description Aspect } & \multicolumn{2}{|l|}{ Structural, Behavioral, Semantic } \\
\hline \multicolumn{2}{|c|}{ Need for Tool Support Analysis } & \multicolumn{2}{|c|}{ Architecture lifecycle: Business case, Creating architecture, Documenting, Analyzing, Evolving } \\
\hline \multicolumn{2}{|c|}{ Usage of Tool Support } & \multicolumn{2}{|c|}{ Simulation, Dependence analysis, Model checking, Conformance testing, Interface consistency, Inspection, and Review-based } \\
\hline \multicolumn{2}{|c|}{ Automation's level } & \multicolumn{2}{|c|}{ Fully automated, Partially automated, Manual } \\
\hline
\end{tabular}




\subsection{Identifying Factors for Lightweight Evaluation Method}

Architecture evaluations are usually performed manually based on informal/semiformal architecture documentation and the reviewer's knowledge [86]. The comprehensive SA evaluation methods, in particular ATAM, require a massive amount of cost and effort. This problem results in lightweight SA evaluation methods. Heavyweight reviews are long-running, documentation-based, such as technical reviews and inspections. While lightweight runs are based on short-running processes with little architecture documentation. The criteria for lightweights have not yet been defined, and they are detectable based on the publication's claim. In this research, ATAM, as the best sample of heavyweight methods, ARIS, BAR, and TARA,-ATAM, ARID, PBAR, and TARA, are lightweight to identify factors for lightweight methods $[87,88]$.

\subsubsection{Architecture Tradeoff Analysis Method}

ATAM is the most mature, sophisticated, and well-known method that various researchers have devised. ATAM-based methods are flexibly used for evaluation purposes, such as the following: seeking SA improvement opportunities, risk analysis, SA comparison, but generally, finding out whether the candidate SA supports business goals adequately. ATAM-based methods engage various stakeholders with various techniques for prioritizing requirements by cumulative voting and utility tree, then identify trade-offs to resolve conflicts.

C1 (Main Goal): identifying SA patterns and tactics suit business derives.

C3 (Covered QAs): All QAs or any property that can affect the business goals.

C4, C5, and C6 (Process): Table 4 explains the ATAM process.

C2 (Evaluation Techniques): Based on scenario and experience.

C7 (Validation): It has been extensively validated.

Outcomes: A list of risks, non-risks, risk-themes, sensitivity points, and trade-off points.

SA description: SA styles and tactics, as well as ATAM-based methods, define a precise template for documenting the quality scenarios.

Tools and techniques: Brainstorming and voting.

Discussion: Although it exploits a scenario-based paradigm, it engages various stakeholders for up to six weeks and is costly. The quality scenarios and ATAM templates represent the requirements in detail, but they are often confusing. Cumulative voting can induce stakeholders into excessive rivalry. Moreover, its reliance on SA documentation and the ignorance of project management paradigms makes ATAM impossible to run for agile projects. 
Table 4. The steps of ATAM.

\begin{tabular}{|c|c|c|c|}
\hline ATAM Step (C5) & Stakeholders Engagement (C4) & How User Experience Interferes with the Method (C6) & Outputs \\
\hline \multicolumn{4}{|l|}{ First Phase: Presentation } \\
\hline 1. Briefing of the ATAM & \multirow{2}{*}{ Evaluation Team and All stakeholders } & $\begin{array}{l}\text { The stakeholders will understand the ATAM process and } \\
\text { related techniques. }\end{array}$ & - \\
\hline 2. Introduction of the business drivers & & $\begin{array}{l}\text { The stakeholders will understand the goals of businesses and } \\
\text { the architectural drivers (non-functional qualities affect SA). }\end{array}$ & - \\
\hline 3. Introduction of SAs & $\begin{array}{l}\text { Evaluation Team and who make significant } \\
\text { project decisions }\end{array}$ & The evaluation team will review the targeted SA. & - \\
\hline 4. Identifying the architectural approaches & Evaluation Team and software architects & $\begin{array}{l}\text { The team and architects will highlight architectural patterns, } \\
\text { tactics, and SA design. }\end{array}$ & List of the candidate SAs design \\
\hline 5. Producing of the quality attribute tree & $\begin{array}{l}\text { Evaluation Team and those who make } \\
\text { significant project decisions }\end{array}$ & $\begin{array}{l}\text { The decision-makers will prioritize their decision based on } \\
\text { the quality attribute goals. }\end{array}$ & $\begin{array}{l}\text { The first version is based on prioritized quality } \\
\text { scenarios and a quality attribute tree. }\end{array}$ \\
\hline 6. Analyze the architectural approaches & Evaluation Team and software architects & $\begin{array}{l}\text { They will link the SA to primary quality attribute goals to } \\
\text { develop an initial analysis resulting in non-risks, risk, and } \\
\text { sensitivity / trade-off points. }\end{array}$ & $\begin{array}{l}\text { The first version of non-risks, risks, risk themes, } \\
\text { trade-off points, sensitivity points }\end{array}$ \\
\hline \multicolumn{4}{|l|}{ Second Phase: Testing } \\
\hline 7. Brainstorming and prioritizing scenarios & Evaluation Team and All stakeholders & $\begin{array}{l}\text { It will utilize the involved stakeholder's knowledge to } \\
\text { expand the quality requirements. }\end{array}$ & The last version of prioritized quality scenarios \\
\hline 8. Analyze the architectural approaches & Evaluation Team and software architects & Revised the achievements. & $\begin{array}{l}\text { The version of the of non-risks, risks, risk themes, } \\
\text { trade-off points, sensitivity points }\end{array}$ \\
\hline \multicolumn{4}{|l|}{ Third Phase: Reporting } \\
\hline 9. Conclusion & All stakeholders & $\begin{array}{l}\text { It summarizes the evaluation's achievements regarding the } \\
\text { business drivers introduced in the second step. }\end{array}$ & Evaluation report with final results \\
\hline
\end{tabular}




\subsubsection{Lightweight ATAM}

Costs of the ATAM-based method derived from Lightweight ATAM requires less than $6 \mathrm{~h}$ running. The technique is used by a development team that is familiar with ATAM, SA, and goals.

C4, C5, and C6 (Process): The evaluation process was created by eliminating or constraining the scope of ATAM's activities, which is shown in Table 4. It assumes the participants are familiar with ATAM while brainstorming and prioritizing are omitted because of their cost.

Steps 1, 7, and 8 are omitted, and steps 2, 3, 4, 5, and 6 should be completed in $15 \mathrm{~min}$. Step 9 should be completed in $30 \mathrm{~min}$.

C7 (Validation): No validation, and the method features generally are as same as ATAM.

Discussion: The method reduces the stakeholder's engagement, and the evaluation process steps, but architecture evaluation still needs more formality. It relies on the stakeholder's familiarity and tactical knowledge, which is achieved because of the full ATAM implementation. It is evident that by constraining the scope and depth of evaluation, a lower effort is needed.

\subsubsection{ARID}

C1 (Main Goal): Detecting of SAs issues to assess the appropriateness of the chosen SA.

C3 (Covered QAs): Applicable for any QA originated from the quality scenarios.

C4, C5, and C6 (Process):

Phase 1: Meeting for preparation.

Step 1: Appointing of reviewers.

Step 2: Presenting of SA's designs.

Step 3: Prepare seed scenarios.

Step 4: Arranging the meeting.

Phase 2: Review meeting.

Step 5: Presenting ARID.

Step 6: Presenting designed SA.

Step 7: Brainstorming and prioritizing the scenarios.

Step 8: Conducting of SA evaluation.

Step 9: Results.

C7 (Validation): One pilot experience in the industry.

C2 (Evaluation Techniques): Based on scenario and expertise.

SA description: There is no specific form of SA designs or documents.

Tools and techniques: Brainstorming and voting.

Outcomes: List of the given SA issues.

Discussion: It is a simple method to seek flaws and weaknesses in QAs of the given SA. ARID does not explicitly state the QAs and SA styles during the analysis. The analysis focuses on a set of properties represented by a group of quality scenarios. It has nine steps, which are not compatible with the lightweight concept. It emphasizes an expert informal review with no particular form of SA style. As a result, it is difficult to repeat.

\subsubsection{PBAR}

ATAM is the most mature, sophisticated, and well-known method that various researchers have devised. ATAM-based methods are flexibly used for evaluation purposes, such as the following: seeking SA improvement opportunities, risk analysis, SA comparison, but generally, finding out whether the candidate SA supports business goals adequately. ATAM-based methods engage various stakeholders with various techniques for prioritizing requirements by cumulative voting and utility tree, then identifying trade-offs to resolve conflicts.

C1 (Main Goal): Detecting quality attribute issues. 
C3 (Covered QAs): Potential risks influencing QAs.

C4, C5, and C6 (Process):

1. Elicitation of essential quality requirements from user stories with the assistance of developers.

2. Establishing SA's structure by a discussion with developers.

3. Nominating architectural styles.

4. Analyzing the nominated architectural effects on the qualities.

5. Recognizing and discussing the final results.

C2 (Evaluation Techniques): It is based on scenario and experience.

C7 (Validation): Nine student small-size projects for industrial use.

SA description: There is no specific form of SA designs or documents, but SA styles are included during the evaluation.

Tool and techniques: Informally requirement elicitation during the development team meeting. Outcomes: It has the QAs issues, which are mismatches between QAs and SA styles.

Discussion: PBAR contains all the criteria of the lightweights. It reduces the process into five steps that occur once in face-to-face meetings with the development team. It omits the prioritizing requirements to help the method. PBAR requires a negligible amount of time to run in comparison with the traditional methods. It focuses on the production step in agile projects. It is operational in the software industry rather than the conventional methods for companies that use agile and lean software development methodologies. It also confines the use of this method comprehensively. The evaluation uses SA styles and tries to find mismatches between SA styles and QAs of candidate SAs. However, it ignores formalizing the assessment technique and merely relies on tacit knowledge of SA styles and their impacts on QAs. Moreover, the influence of styles on QAs is not conclusive in most cases since other factors should be taken into account.

\subsubsection{TARA}

C1 (Main Goal): Indicating the proper SA of crucial requirements.

C3 (Covered QAs): QAs and even functional requirements.

C4, C5, and C6 (Process):

1. The evaluator elicits essential requirements and system context.

2. The evaluator designed SA based on the previous.

3. The implementation techniques are assessed.

4. The results of the previous step should link to the requirements. Expert judgment techniques are applied in this step.

5. The evaluation's results should be collected and related based on the predefined forms.

6. Present findings and recommendations.

C2 (Evaluation Techniques): Metric-based.

C7 (Validation): TARA has been validated in the industry.

SA description: There is no specific form of SA designs or documents, but the evaluator should understand functional/deployment structures and system context.

Tool and techniques: The method involves automated code analysis techniques (module dependencies, size measures, code metrics, and test coverage). For implemented software exploits information on software execution (e.g., event logs).

Outcome: a list of crucial requirements with its relevant SA.

Discussion: TARA is a lightweight permissive method that does not exclude requirements specification documents. It allows an evaluator to consult with the stakeholders to prioritize the requirements. TARA suits the implemented software since it uses code analysis techniques with operational data. Evaluation methods mainly rely on explicit scenarios and the architect's knowledge, but TARA relies on the reviewer's judgment associated with the SA analysis evidence. Consequently, it just works well for implemented software in the maintenance phase when it is hard to correct the flaws. 


\subsubsection{DCAR}

C1 (Main Goal): Suitability of architectural decisions.

C3 (Covered QAs): A set of architectural decisions.

C4, C5, and C6 (Process):

1. Preparation: The SA styles and related technologies are presented for management and customer representatives.

2. DCAR Introduction.

3. Management presentation: The management/customer representative will be exposed to a brief presentation to elicit the potential decision forces (the list of architectural decisions was produced in the first step).

4. Architecture presentation: The lead architect will present potential decision forces and potential design decisions to all participants in a very brief and interactive session to revise the list of architectural choices.

5. Forces and decision completion: The decision forces and design decisions will be verified based on the same terminologies for all stakeholders.

6. Decision prioritization: The decisions will be prioritized based on participant's votes.

7. Decision documentation: The most important decisions will be documented in applied architectural solutions, the addressed problem, the alternative solutions, and the forces that must be considered to evaluate the decision.

8. Decision evaluation: By discussion among all stakeholders, the potential risks and issues are selected, the decisions are revised based on decision approval.

9. Retrospective and reporting: Review team will scrutinize all the artifacts and produce the final report.

C3 (Evaluation technique): Experience-based and expert reasoning.

C7 (Validation): It has been verified in five large industrial projects.

SA Description: SA design, informal requirements, and business drivers.

Output: Issues and risks.

Tools and technique: Templates, wiki, and UML tools.

Discussion: DCAR originated from SA evaluation experiences in the industry. It is a lightweight method that allows users to analyze and record the rationale behind architectural decisions systematically. In comparison, scenario-based methods test SAs against scenarios to find flaws and issues in a specific QA. For the sake of being lightweight, brainstorming and prioritizing steps are omitted. The reviewers should know SA and rely on the standard UML tool to make the evaluation understandable for stakeholders. Although it provides comprehensive templates for assessment, it considers several factors that originated from managerial views. This consideration leads to the nine steps, which are not compatible with lightweights.

\subsection{Factors for Lightweight Evaluation Method}

The five lightweight methods plus ATAM are compared in Table 5 based on the following most common aspects: the evaluation methods, SA description, evaluation time, method's validation, and tool support. These aspects are categorized based on the comparison framework reflected in Table 3, and the approaches are related to them.

Table 5. Lightweight methods comparison.

\begin{tabular}{ccc}
\hline Aspect & Category & Approaches \\
\hline \multirow{2}{*}{ The goal of the evaluation method } & Assessment against requirements & Lightweight ATAM \\
\cline { 2 - 3 } & Architectural flaws detection & PBAR, TARA, ARID \\
\hline
\end{tabular}


Table 5. Cont.

\begin{tabular}{|c|c|c|}
\hline Aspect & Category & Approaches \\
\hline \multirow{4}{*}{ SA description } & Architectural decisions & DCAR \\
\hline & Full SA description (views) & Lightweight-ATAM \\
\hline & SA patterns, tactics & PBAR \\
\hline & $\begin{array}{l}\text { There is no specific form of SA designs } \\
\text { or documents }\end{array}$ & ARID, PBAR, TARA \\
\hline \multirow{3}{*}{ Time of evaluation } & Early & DCAR \\
\hline & Middle & ARID, PBAR, Lightweight-ATAM \\
\hline & Post-deployment & TARA \\
\hline \multirow{4}{*}{$\begin{array}{l}\text { Method's validation based on case } \\
\text { study number }\end{array}$} & 0 & Lightweight-ATAM \\
\hline & 1 & TARA \\
\hline & 3 to 6 & PBAR, DCAR \\
\hline & $6+$ & ATAM \\
\hline \multirow{2}{*}{ Tool Support } & Conformance testing & TARA \\
\hline & Review-based & DCAR \\
\hline
\end{tabular}

\subsubsection{Covering Early and Late Methods}

SA has been evaluated at various points in the software life cycle. It can happen at the early and late stages of the development life cycle. Early methods evaluate SA candidates before the implementation, while late methods assess the system's implemented versions compared to the planned/previous versions. Early methods are based on SA descriptions and other sources of information. These methods lead to a better understanding of SA and the identification of problems with the architecture. At the same time, late processes utilize data obtained from the actual software implementation. Hence, the existing architecture can be reconstructed to compare with early evaluated SA. Early methods mostly contain scenario-based, mathematical-model-based, and simulation-based, while late ones are mostly metrics-based and tool-based. Early methods emphasize designing and modeling while late ones try to catch code violations and module inconsistencies. Sometimes, early methods can evaluate the implemented software $[89,90]$. While late and early evaluation is not contradictory, they can mostly not be attended simultaneously due to the overload they imbue on the approach. As it is indicated in the time of the evaluation part of Table 5, no method can cover all the stages.

\subsubsection{Need of Agility}

Although SA evaluation is beneficial, it is not broadly applied in the industry nowadays. Even agile development approaches do not encourage using architecture evaluation methods since they usually take a considerable amount of time and resources [91,92]. Except for PBAR and DCAR, the other methods are not proper for agile projects.

\subsubsection{Ad Hoc Analysis}

Ad hoc analysis ties architecture analysis to architecture design and implementation activities employing experience, expertise, and argumentation [93]. Informal experiencebased architecture analysis is prevalent, as this method works regardless of architecture documentation. This analysis is carried out manually by several SA studies $[94,95]$. 


\section{Targeted Quality Attributes: Performance and Security in Software Architecture Evaluation}

Based on "software architecture definition differences" in this research, performance and security are selected as the targeted QAs. These QAs will be discussed in the following subsections. The QAs belong to the methods represented in Table 2.

\subsection{Performance}

Mostly, the performance is estimated based on the approximate model of the runtime view. These methods need appropriate descriptions of the dynamic behaviors of SA to show the characteristics of the components, frequency, and nature of inter-component communication. Mathematical formalism such as Petri net and simulation boost this estimation [96]. Figure 2 [48] shows that most SA performance analysis methods convert SA specifications to desirable models. Subsequently, timing data is added to the models to estimate performance attributes and provide the following feedback:

i. Predicting the system's performance in the early stages of the software life cycle.

ii. Testing performance goals.

iii. Comparing the performance of architectural designs.

iv. Finding bottleneck, possible timing problems.

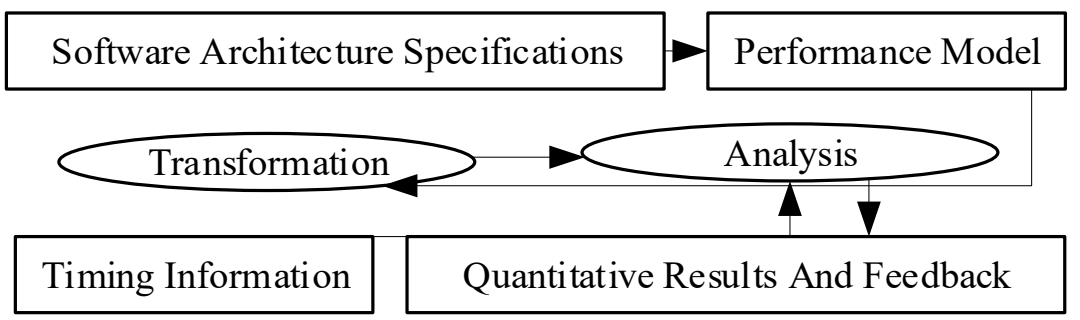

Figure 2. Software architecture-based performance analysis.

Some of the essential methods are discussed in the following: CF is a mathematical model-based method that integrates performance analysis into the software development cycle. It presents software execution behaviors through a graph, including arcs and nodes, with timing information. This model works based on the Queuing Networks Model (QNM) performance model. The simulation evaluates the model to estimate performance attributes. The approach has been enriched by using Kruchten's $4+1$ views and using use case scenarios depicted by a message sequence chart as the dynamic behavior of SA. Later on, the approaches combine UML diagram information to create a performance model of SA more formally. However, the methods do not consider the concurrent/non-deterministic behaviors of the components during QNM modeling. In order to address these problems, the labeled transition system (LTS) graph and ADL were added to the approaches [97,98]. The emerging problem was the computational complexity of the possible state space explosion of the architecture description's finite-state model. This problem persuades experienced-based analysis methods such as ABAS to not use an analysis tool to evaluate performance [99].

PASA boosts SPE by adding performance anti-patterns and architectural styles. It tries to adapt the concept of ATAM and SAAM into SPE. PASA formally states the scenarios with a descriptive architecture language such as the UML sequence diagram [100].

Nevertheless, none of these approaches has yet been applied to a complete environment for performance analysis, specification, and providing feedback to the designer. The unsolved problem is automating completely derived performance models from the software specification and assimilating the supporting tools in a comprehensive environment [101]. Moreover, although the quality of models has not yet been attended to deeply, high-quality models are an essential factor in which verification and performance analysis strongly rely on them [102]. 


\subsection{Security}

Security is a complex technical topic that can only be treated superficially at architectural levels. Although scenario-based methods are typically used for SA security analysis, security differs from other quality attributes. The security requirements are not enough for constructing a "security scenario" by themselves [103]. At the same time, it is necessary to understand the precise security requirements of an application and devise mechanisms to support SA security. In the implementation layer of SA, there are many techniques such as Windows operational security, Java Authentication and Authorization Service (JAAS), and without any significant problems [104]. These techniques mitigate the principal threats: authorization violation, system penetration, integrity compromise, confidentiality disclosure, repudiation, and denial of service.

The most important problem is that distributed SA has multiple layers of abstraction. Once each service abstracts the lower layer's business functionality, it is needed to abstract the underlying application's user identity context. Combining with the individual backends, heterogeneous security concepts beget a long way from the first request for a business procedure to the systems. Therefore, it also comprises monitoring, logging, and tracing all data flows related to security [105]. Security architectural flaws can be omissions, commissions, and realization flaws [106].

- Omission flaws are born in the aftermath of decisions that have never been made (e.g., ignoring a security requirement or potential threats). Experience and prototype-based or even scenario-based methods can help the architect to detect this type of flaw. Still, they are mainly concerned with the requirement elicitation step, which is outside the scope of this research.

- Commission flaws refer to the design decisions that were made and could lead to undesirable consequences. An example of such flaws is "using a weak cryptography for passwords" to achieve better performance while maintaining data confidentiality. DCAR is devised to support such a problem.

- Realization flaws are the correct design decisions (i.e., they satisfy the software's security requirements), but their implementation suffers from coding mistakes. It can lead to many consequences, such as crashes or bypass mechanisms. TARA and SA evaluation methods can mitigate these problems.

In the industry, commission and omission flaws happen due to inexperienced decisions. The realization flaws are mostly ignored due to the cost of the detective methods. As a result, this current research highlights the realization flaws.

An SA model has properties such as performance or security. Regularly, these properties are emergent, and it is more feasible to reason about emergent properties in simpler models than complex ones. So, it is needed to simplify your model to leverage the problem and prove your knowledge about the emergent properties [107].

\section{Identified Features and Factors}

The study was devised to identify the features and lightweight factors to boost an evaluation framework. Concerning this fact, the study sought the practitioner's needs and the tendencies that researchers have paid attention to. Figure 3 shows the relationships and basis for identifying the features and factors. Then Table 6 lists the specified features and lightweight characteristics acquired from the study. Figure 3 shows how this research applies text analysis and data mining to the comprehensive online definitions of SA and the pool of papers published in the last three decades. In the next step, a comparison framework was defined, and six approaches were inspected deeply to find features and factors. 
Table 6. The identified features and lightweight's factors.

\begin{tabular}{|c|c|c|}
\hline \multicolumn{2}{|c|}{ Features } & Lightweights Factors \\
\hline \multirow{3}{*}{ The excess of the SA Evaluation work: } & \multirow{3}{*}{ Lightweight } & Covering Early and late methods \\
\hline & & Need of agility \\
\hline & & Ad hoc analysis \\
\hline Scope of the SA Evaluation: & \multicolumn{2}{|c|}{ Distributed and heterogamous system } \\
\hline Style of evaluated SA: & \multicolumn{2}{|c|}{ SOA, Component-based pipe and filter } \\
\hline SA presentation: & \multicolumn{2}{|c|}{ Petri nets } \\
\hline Targeted quality attributes: & \multicolumn{2}{|c|}{ Performance and security } \\
\hline Tools and technique: & \multicolumn{2}{|c|}{ Should be investigated } \\
\hline
\end{tabular}

First of all, two categories of SA definition were elicited from the online repository. In the next step, the keywords in practitioners' reports differed from the keywords of researchers. The top keywords are "time, cost, distributed, and complexity", which means the practitioners needed a lightweight solution. "Distributed" refers to the scope of the evaluation. Secondly, based on the 811 published studies from 1999 to 2016 in SA's topics, "security and performance analysis, heterogeneity and distributed, and agility" were the most popular research topics. Similar to a practitioner's concerns, heterogeneity and distribution refer to the scope. Security and performance were selected as the targeted quality attributes (TQA) for evaluation. Agility was the same as one of the identified factors for lightweights.

Component-Based architecture, $\mathrm{SOA}$, and pipe and filter styles were selected as the identified scope's proper SA styles. As mentioned in Sections 3, 4 and 5.1, Petri net's formalism and visual presentation, hierarchical colored Petri net, is chosen to present SA due to its supremacy over other SA presentation methods.

For the sake of research concerns, 76 articles with SA evaluation topics were selected out of 811 articles. Next, 27 SA evaluation methods were chosen for the review. These methods were reviewed based on the following two aspects: the technique and popularity in the industry. The comparison framework was defined to compare the evaluation methods. Then five lightweight methods were selected and compared with ATAM. Consequently, three lightweight factors were identified. Moreover, (TQA1) performance and (TQA2) security were reviewed throughout 27 evaluation methods. As mentioned many times in this study, the SA evaluation approaches are devised to help software architects make a proper decision. Obviously, the architects are interfering in many steps to heighten the evaluation process, so the SA evaluation tends to be more manual rather than automated. Architects' skills may impact the design and decision-making parts that are outside the scope of this research.

Based on identified features, factors, and comparison framework, the overall profile of a lightweight evaluation framework is described below as follows:

This study replied to research question two by distinguishing the differences between practitioners' and researchers' perspectives on SA via the comparative text analysis of SA definitions and the systematic literature review of existing methods. Then, for the sake of the first research question, this exploratory research identified the features and characteristics that enable lightweight SA evaluations in the industry. An evaluation framework can boost its usage by detecting flaws and issues in SA's performance and security. An informal description of requirements, UML diagrams, and source code is the input of the framework. The framework works within the specific scope of distributed software with the mentioned SA styles. The procedure for stakeholders is the minimal process, which was elicited from reviewing the lightweight solutions. The procedure is a face-to-face meeting between the architect and internal/external reviewers who know SA. The tools and techniques should be investigated to ease the integration of features and factors. 


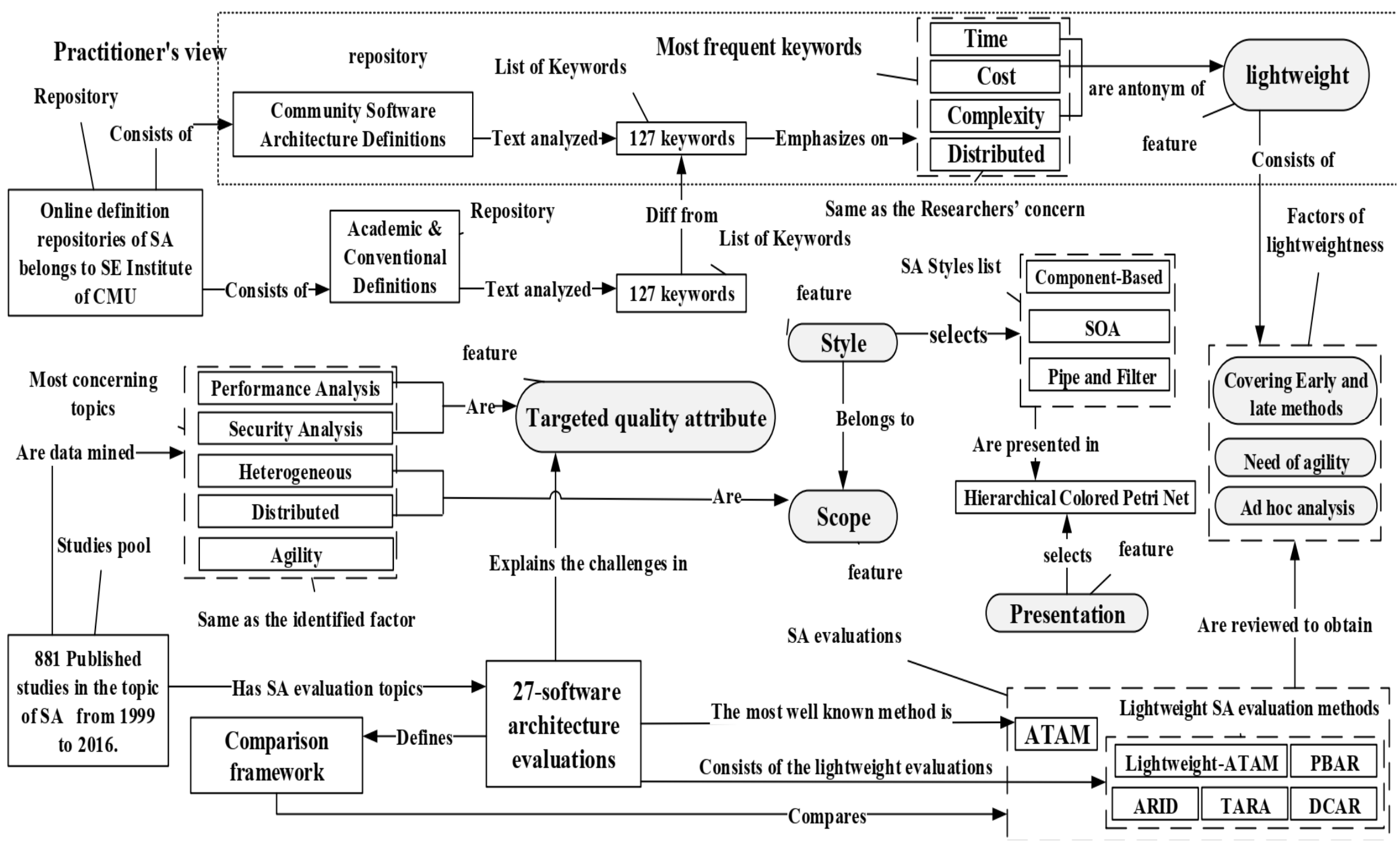

Figure 3. Identifying features and lightweight factors. 


\section{Achievement and Results}

The existing literature was reviewed to remind us of the past research on using SA evaluation methods to identify the proposed framework's main features in the first stage. In the second stage, the factors affecting lightweights are identified. These factors improve the SA evaluation framework used in the industry.

In the first stage, the SA evaluation framework's features were identified based on the text analysis of researchers' and practitioners' SA definitions and all published studies for the last three decades on SA's topics. This analysis concluded that a lightweight SA evaluation solution was needed to uncover distributed and heterogeneous software's security and performance problems. Consequently, the security and performance analysis of SA were reviewed, and the proper SA presentation and styles for the distributed and heterogeneous software were identified.

In the second stage, lightweights were identified from the weaknesses of the current state of the art in the lightweight SA analysis methods. Indeed, the study tried to bridge the gap of less usage of systematic SA evaluations in the industry. First, it should be clear why the industry refrains from SA evaluation methods proposed by academics. As a result, this study followed two strands of academic and practitioner concerns. The practitioners need the SA evaluation framework with specific industrial features to solve their current problems, while academics focus primarily on scientific issues and possible issues in the future. This mindset led us to analyze the online web repository of SA definitions. As a result of that, the main extracted features that are in demand for both sides were a lightweight framework that can evaluate heterogeneous software systems from a performance and security perspective.

Moreover, the study conducted a systematic literature review on SA evaluation methods. As a result, the SA evaluation comparison framework was proposed as a basis for the SA evolution comparison. Then, it narrowed down the literature to the lightweight SA evaluation methods. A total of six SA evaluation methods were studied deeply to identify the factors influencing the SA evaluation method.

\section{Conclusions}

Although SA evaluation methods are beneficial, they are not broadly applied in the industry [108,109]. The selected SA evaluation methods are reviewed comprehensively. This research focuses on SA architecture, design, and its evaluation. It introduces the comparison framework to compare existing methods. The comparison between ATAM, as the heavyweight method's pinnacle, and the five fashionable lightweight methods recognizes three main factors for lightweights. A total of five different steps have been taken to address this problem. Firstly, the differences between academic and practitioner definitions of SA prove that the industry needs a lightweight SA evaluation method. Secondly, it is noticed that SA research mainly focuses on "performance and security analysis". Finally, these are the main features and factor that have been identified. As a result, the literature review explored SA evaluation methods to categorize them to understand the factors that hinder the lightweight SA evaluation method's success. The research suggests further investigation to find the proper tools and techniques to ease the integration of features and factors and boost solution usage in the industry.

Author Contributions: Conceptualization: M.S., R.C.M. and Z.S.; Methodology: M.S. and Z.S.; Visualization: Z.S. and F.Q., Writing—original draft preparation: M.S. and R.C.M., Writing—review and editing: F.Q. and R.C.M.; Funding acquisition: Z.S. All authors have read and agreed to the published version of the manuscript.

Funding: This paper is supported by Ministry of Higher Education of Malaysia, Grant number: KKP/2020/UKM-UKM/4/3.

Institutional Review Board Statement: Not applicable.

Informed Consent Statement: Not applicable. 
Data Availability Statement: Not applicable.

Conflicts of Interest: The authors declare no conflict of interest.

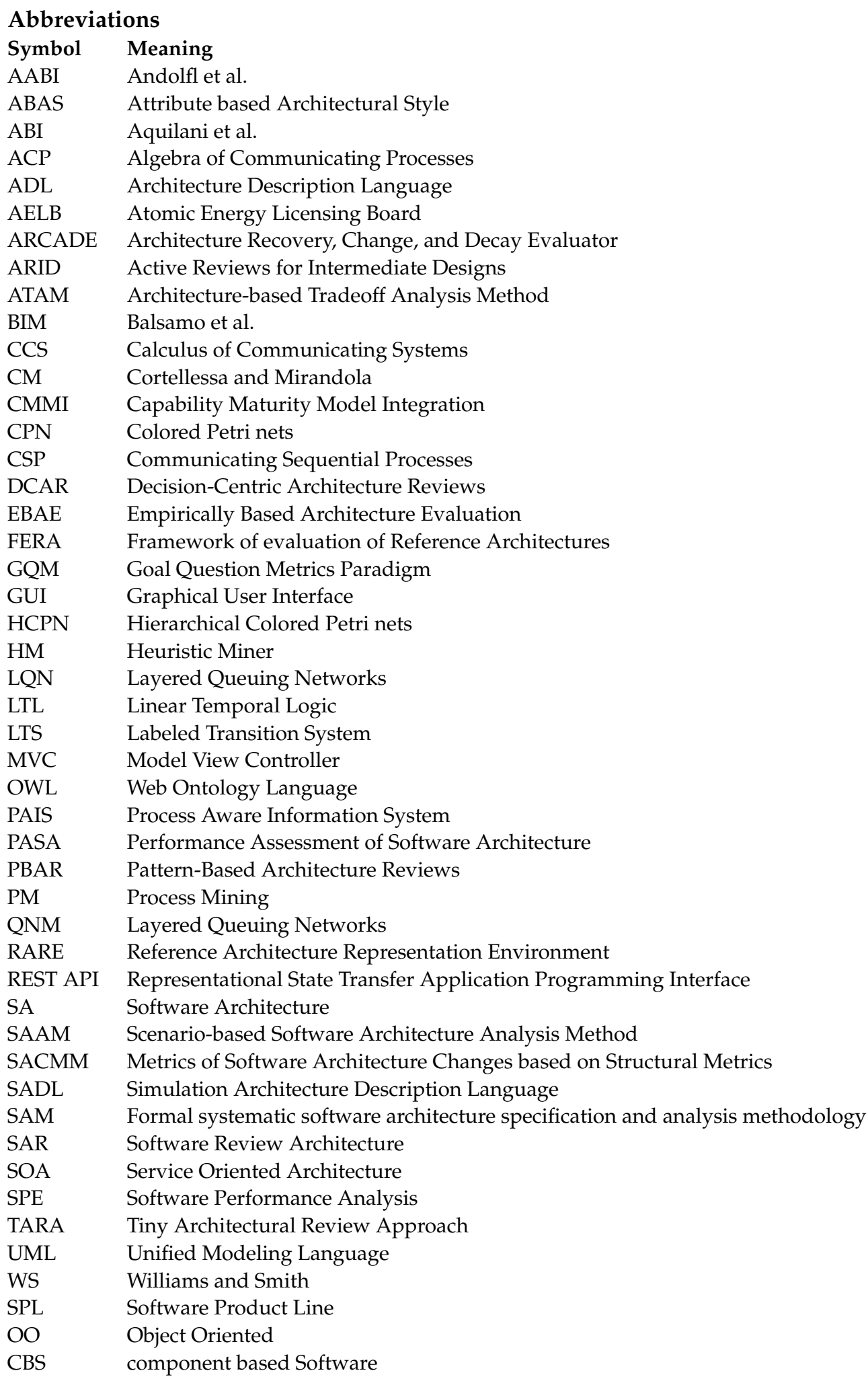




\section{References}

1. Feldgen, M.; Clua, O. Promoting design skills in distributed systems. In Proceedings of the 2012 Frontiers in Education Conference Proceedings, Seattle, WA, USA, 3-6 October 2012; IEEE: Piscataway, NJ, USA, 2012; pp. 1-6.

2. Heidmann, E.F.; von Kurnatowski, L.; Meinecke, A.; Schreiber, A. Visualization of Evolution of Component-Based Software Architectures in Virtual Reality. In Proceedings of the 2020 Working Conference on Software Visualization (VISSOFT), Adelaide, Australia, 28 September-2 October 2020; IEEE: Piscataway, NJ, USA, 2020; pp. 12-21.

3. Mekni, M.; Buddhavarapu, G.; Chinthapatla, S.; Gangula, M. Software Architectural Design in Agile Environments. J. Comput. Commun. 2017, 6, 171-189. [CrossRef]

4. Kil, B.-H.; Park, J.-S.; Ryu, M.-H.; Park, C.-Y.; Kim, Y.-S.; Kim, J.-D. Cloud-Based Software Architecture for Fully Automated Point-of-Care Molecular Diagnostic Device. Sensors 2021, 21, 6980. [CrossRef]

5. Lagsaiar, L.; Shahrour, I.; Aljer, A.; Soulhi, A. Modular Software Architecture for Local Smart Building Servers. Sensors 2021, 21, 5810. [CrossRef] [PubMed]

6. Ungurean, I.; Gaitan, N.C. A software architecture for the Industrial Internet of Things-A conceptual model. Sensors 2020, 20, 5603. [CrossRef] [PubMed]

7. Piao, Y.C.K.; Ezzati-Jivan, N.; Dagenais, M.R. Distributed Architecture for an Integrated Development Environment, Large Trace Analysis, and Visualization. Sensors 2021, 21, 5560. [CrossRef]

8. Dickerson, C.E.; Wilkinson, M.; Hunsicker, E.; Ji, S.; Li, M.; Bernard, Y.; Bleakley, G.; Denno, P. Architecture definition in complex system design using model theory. IEEE Syst. J. 2020, 15, 1847-1860. [CrossRef]

9. Yang, C.; Liang, P.; Avgeriou, P.; Eliasson, U.; Heldal, R.; Pelliccione, P. Architectural assumptions and their management in industry-An exploratory study. In Proceedings of the European Conference on Software Architecture, Canterbury, UK, 11-15 September 2017; Springer: Berlin/Heidelberg, Germany, 2017; pp. 191-207.

10. Harrison, N.; Avgeriou, P. Pattern-based architecture reviews. IEEE Softw. 2010, 28, 66-71. [CrossRef]

11. Yang, T.; Jiang, Z.; Shang, Y.; Norouzi, M. Systematic review on next-generation web-based software architecture clustering models. Comput. Commun. 2020, 167, 63-74. [CrossRef]

12. Allian, A.P.; Sena, B.; Nakagawa, E.Y. Evaluating variability at the software architecture level: An overview. In Proceedings of the 34th ACM/SIGAPP Symposium on Applied Computing, Limassol, Cyprus, 8-12 April 2019; pp. 2354-2361.

13. Sedaghatbaf, A.; Azgomi, M.A. SQME: A framework for modeling and evaluation of software architecture quality attributes. Softw. Syst. Model. 2019, 18, 2609-2632. [CrossRef]

14. Venters, C.C.; Capilla, R.; Betz, S.; Penzenstadler, B.; Crick, T.; Crouch, S.; Nakagawa, E.Y.; Becker, C.; Carrillo, C. Software sustainability: Research and practice from a software architecture viewpoint. J. Syst. Softw. 2018, 138, 174-188. [CrossRef]

15. van Heesch, U.; Eloranta, V.-P.; Avgeriou, P.; Koskimies, K.; Harrison, N. Decision-centric architecture reviews. IEEE Softw. 2013, 31, 69-76. [CrossRef]

16. Zalewski, A. Modelling and evaluation of software architectures. In Prace Naukowe Politechniki Warszawskiej. Elektronika; Warsaw University of Technology Publishing Office: Warsaw, Poland, 2013.

17. Amirat, A.; Anthony, H.-K.; Oussalah, M.C. Object-oriented, component-based, agent oriented and service-oriented paradigms in software architectures. Softw. Archit. 2014, 1. [CrossRef]

18. Richards, M. Software Architecture Patterns; O’Reilly Media: Newton, MA, USA, 2015. Available online: https://www.oreilly.com/ library/view/software-architecture-patterns/9781491971437/ (accessed on 1 December 2021).

19. Shatnawi, A. Supporting Reuse by Reverse Engineering Software Architecture and Component from Object-Oriented Product Variants and APIs. Ph.D. Thesis, University of Montpellier, Montpellier, France, 2015.

20. Brown, S. Is Software Architecture important. In Software Architecture for Developers; Leanpub: Victoria, BC, Canada, 2015.

21. Link, D.; Behnamghader, P.; Moazeni, R.; Boehm, B. Recover and RELAX: Concern-oriented software architecture recovery for systems development and maintenance. In Proceedings of the 2019 IEEE/ACM International Conference on Software and System Processes (ICSSP), Montreal, QC, Canada, 25-26 May 2019; IEEE: Piscataway, NJ, USA, 2019; pp. 64-73.

22. Medvidovic, N.; Taylor, R.N. Software architecture: Foundations, theory, and practice. In Proceedings of the 2010 ACM/IEEE 32nd International Conference on Software Engineering, Cape Town, South Africa, 1-8 May 2010; IEEE: Piscataway, NJ, USA, 2010; Volume 2, pp. 471-472.

23. Kazman, R.; Bass, L.; Klein, M.; Lattanze, T.; Northrop, L. A basis for analyzing software architecture analysis methods. Softw. Qual. J. 2005, 13, 329-355. [CrossRef]

24. Tibermacine, C.; Sadou, S.; That, M.T.T.; Dony, C. Software architecture constraint reuse-by-composition. Future Gener. Comput. Syst. 2016, 61, 37-53. [CrossRef]

25. Muccini, H. Exploring the Temporal Aspects of Software Architecture. In Proceedings of the ICSOFT-EA 2016, Lisbon, Portugal, 24-26 July 2016; p. 9.

26. Aboutaleb, H.; Monsuez, B. Measuring complexity of system/software architecture using Higraph-based model. In Proceedings of the International Multiconference of Engineers and Computer Scientists, Hong Kong, China, 15-17 March 2017; Newswood Limited: Hong Kong, China, 2017; Volume 1, pp. 92-96.

27. Garcés, L.; Oquendo, F.; Nakagawa, E.Y. Towards a taxonomy of software mediators for systems-of-systems. In Proceedings of the VII Brazilian Symposium on Software Components, Architectures, and Reuse, Sao Carlos, Brazil, 17-21 September 2018; pp. 53-62. 
28. Magableh, A.; Shukur, Z. Comprehensive Aspectual UML approach to support AspectJ. Sci. World J. 2014, 2014, 327808. [CrossRef]

29. Kanade, A. Event-Based Concurrency: Applications, Abstractions, and Analyses. In Advances in Computers; Elsevier: Amsterdam, The Netherlands, 2019; Volume 112, pp. 379-412.

30. Al Rawashdeh, H.; Idris, S.; Zin, A.M. Using Model Checking Approach for Grading the Semantics of UML Models. In Proceedings of the International Conference Image Processing, Computers and Industrial Engineering (ICICIE'2014), Kuala Lumpur, Malaysia, 15-16 January 2014.

31. Rodriguez-Priego, E.; García-Izquierdo, F.J.; Rubio, Á.L. Modeling issues: A survival guide for a non-expert modeler. In Proceedings of the International Conference on Model Driven Engineering Languages and Systems, Oslo, Norway, 3-8 October 2010; Springer: Berlin/Heidelberg, Germany, 2010; pp. 361-375.

32. Medvidovic, N.; Taylor, R.N. A classification and comparison framework for software architecture description languages. IEEE Trans. Softw. Eng. 2000, 26, 70-93. [CrossRef]

33. Jensen, K.; Kristensen, L.M. Introduction to Modelling and Validation. In Coloured Petri Nets; Springer: Berlin/Heidelberg, Germany, 2009; pp. 1-12.

34. Emadi, S.; Shams, F. Mapping Annotated Use Case and Sequence Diagrams to a Petri Net Notation for Performance Evaluation. In Proceedings of the Second International Conference on Computer and Electrical Engineering (ICCEE'09), Dubai, United Arab Emirates, 28-30 December 2009; pp. 67-81.

35. Sahlabadi, M.; Muniyandi, R.C.; Shukor, Z.; Sahlabadi, A. Heterogeneous Hierarchical Coloured Petri Net Software/Hardware Architectural View of Embedded System based on System Behaviours. Procedia Technol. 2013, 11, 925-932. [CrossRef]

36. Sievi-Korte, O.; Richardson, I.; Beecham, S. Software architecture design in global software development: An empirical study. J. Syst. Softw. 2019, 158, 110400. [CrossRef]

37. Jaiswal, M. Software Architecture and Software Design. Int. Res. J. Eng. Technol. (IRJET) 2019, 6, 2452-2454. [CrossRef]

38. Hofmeister, C.; Kruchten, P.; Nord, R.L.; Obbink, H.; Ran, A.; America, P. Generalizing a model of software architecture design from five industrial approaches. In Proceedings of the 5th Working IEEE/IFIP Conference on Software Architecture (WICSA'05), Pittsburgh, PA, USA, 6-10 November 2005; IEEE: Piscataway, NJ, USA, 2005; pp. 77-88.

39. Wu, X.-W.; Li, C.; Wang, X.; Yang, H.-J. A creative approach to reducing ambiguity in scenario-based software architecture analysis. Int. J. Autom. Comput. 2019, 16, 248-260. [CrossRef]

40. Iacob, M.-E. Architecture analysis. In Enterprise Architecture at Work; Springer: Berlin/Heidelberg, Germany, 2017 ; pp. $215-252$.

41. Al-Tarawneh, F.; Baharom, F.; Yahaya, J.H. Toward quality model for evaluating COTS software. Int. J. Adv. Comput. Technol. 2013, 5,112 .

42. Khatchatoorian, A.G.; Jamzad, M. Architecture to improve the accuracy of automatic image annotation systems. IET Comput. Vis. 2020, 14, 214-223. [CrossRef]

43. Júnior, A.A.; Misra, S.; Soares, M.S. A systematic mapping study on software architectures description based on ISO/IEC/IEEE 42010: 2011. In Proceedings of the International Conference on Computational Science and Its Applications, Saint Petersburg, Russia, 1-4 July 2019; Springer: Berlin/Heidelberg, Germany, 2019; pp. 17-30.

44. Weinreich, R.; Miesbauer, C.; Buchgeher, G.; Kriechbaum, T. Extracting and facilitating architecture in service-oriented software systems. In Proceedings of the 2012 Joint Working IEEE/IFIP Conference on Software Architecture and European Conference on Software Architecture, Helsinki, Finland, 20-24 August 2012; IEEE: Piscataway, NJ, USA, 2012; pp. 81-90.

45. Cabac, L.; Haustermann, M.; Mosteller, D. Software development with Petri nets and agents: Approach, frameworks and tool set. Sci. Comput. Program. 2018, 157, 56-70. [CrossRef]

46. Cabac, L.; Mosteller, D.; Wester-Ebbinghaus, M. Modeling organizational structures and agent knowledge for Mulan applications. In Transactions on Petri Nets and Other Models of Concurrency IX; Springer: Berlin/Heidelberg, Germany, 2014; pp. 62-82.

47. Siefke, L.; Sommer, V.; Wudka, B.; Thomas, C. Robotic Systems of Systems Based on a Decentralized Service-Oriented Architecture. Robotics 2020, 9, 78. [CrossRef]

48. Hasselbring, W. Software architecture: Past, present, future. In The Essence of Software Engineering; Springer: Cham, Switzerland, 2018; pp. 169-184.

49. Breivold, H.P.; Crnkovic, I. A systematic review on architecting for software evolvability. In Proceedings of the 201021 st Australian Software Engineering Conference, Auckland, New Zealand, 6-9 April 2010; IEEE: Piscataway, NJ, USA, 2010 ; pp. 13-22.

50. Barcelos, R.F.; Travassos, G.H. Evaluation Approaches for Software Architectural Documents: A Systematic Review. In Proceedings of the CIbSE 2006, La Plata, Argentina, 24-28 April 2006; pp. 433-446.

51. Patidar, A.; Suman, U. A survey on software architecture evaluation methods. In Proceedings of the 2015 2nd International Conference on Computing for Sustainable Global Development (INDIACom), New Delhi, India, 11-13 March 2015; IEEE: Piscataway, NJ, USA, 2015; pp. 967-972.

52. Shanmugapriya, P.; Suresh, R. Software architecture evaluation methods-A survey. Int. J. Comput. Appl. 2012, 49, 19-26. [CrossRef]

53. Roy, B.; Graham, T.N. Methods for evaluating software architecture: A survey. Sch. Comput. TR 2008, 545, 82.

54. Mattsson, M.; Grahn, H.; Mårtensson, F. Software architecture evaluation methods for performance, maintainability, testability, and portability. In Proceedings of the Second International Conference on the Quality of Software Architectures, Västerås, Sweden, 27-29 June 2006; Citeseer: Princeton, NJ, USA, 2006. 
55. Christensen, H.B.; Hansen, K.M. An empirical investigation of architectural prototyping. J. Syst. Softw. 2010, 83, 133-142. [CrossRef]

56. Babar, M.A.; Gorton, I. Comparison of scenario-based software architecture evaluation methods. In Proceedings of the 11th Asia-Pacific Software Engineering Conference, Busan, Korea, 30 November-3 December 2004; IEEE: Piscataway, NJ, USA, 2004; pp. 600-607.

57. Maranzano, J.F.; Rozsypal, S.A.; Zimmerman, G.H.; Warnken, G.W.; Wirth, P.E.; Weiss, D.M. Architecture reviews: Practice and experience. IEEE Softw. 2005, 22, 34-43. [CrossRef]

58. Babar, M.A. Making software architecture and agile approaches work together: Foundations and approaches. In Agile Software Architecture; Elsevier: Amsterdam, The Netherlands, 2014; pp. 1-22.

59. Sharma, T.; Suryanarayana, G.; Samarthyam, G. Refactoring for Software Design Smells: Managing Technical Debt; Morgan Kaufmann Publishers: Burlington, MA, USA, 2015.

60. Lindvall, M.; Tvedt, R.T.; Costa, P. An empirically-based process for software architecture evaluation. Empir. Softw. Eng. 2003, 8, 83-108. [CrossRef]

61. Santos, J.F.M.; Guessi, M.; Galster, M.; Feitosa, D.; Nakagawa, E.Y. A Checklist for Evaluation of Reference Architectures of Embedded Systems (S). SEKE 2013, 13, 1-4.

62. De Oliveira, L.B.R. Architectural design of service-oriented robotic systems. Ph.D. Thesis, Universite de Bretagne-Sud, Lorient, France, 2015.

63. Nakamura, T.; Basili, V.R. Metrics of software architecture changes based on structural distance. In Proceedings of the 11th IEEE International Software Metrics Symposium (METRICS’05), Como, Italy, 19-22 September 2005; IEEE: Piscataway, NJ, USA, 2005 ; p. 24.

64. Knodel, J.; Naab, M. How to Evaluate Software Architectures: Tutorial on Practical Insights on Architecture Evaluation Projects with Industrial Customers. In Proceedings of the 2017 IEEE International Conference on Software Architecture Workshops (ICSAW), Gothenburg, Sweden, 5-7 April 2017; IEEE: Piscataway, NJ, USA, 2017; pp. 183-184.

65. Babar, M.A.; Gorton, I. Software architecture review: The state of practice. Computer 2009, 42, 26-32. [CrossRef]

66. Tekinerdoğan, B.; Akşit, M. Classifying and evaluating architecture design methods. In Software Architectures and Component Technology; Springer: Berlin/Heidelberg, Germany, 2002; pp. 3-27.

67. Klein, M.H.; Kazman, R.; Bass, L.; Carriere, J.; Barbacci, M.; Lipson, H. Attribute-based architecture styles. In Proceedings of the Working Conference on Software Architecture, San Antonio, TX, USA, 22-24 February 1999; Springer: Berlin/Heidelberg, Germany, 1999; pp. 225-243.

68. Arvanitou, E.M.; Ampatzoglou, A.; Chatzigeorgiou, A.; Galster, M.; Avgeriou, P. A mapping study on design-time quality attributes and metrics. J. Syst. Softw. 2017, 127, 52-77. [CrossRef]

69. Fünfrocken, M.; Otte, A.; Vogt, J.; Wolniak, N.; Wieker, H. Assessment of ITS architectures. IET Intell. Transp. Syst. 2018, 12, 1096-1102.

70. Babar, M.A.; Shen, H.; Biffl, S.; Winkler, D. An Empirical Study of the Effectiveness of Software Architecture Evaluation Meetings. IEEE Access 2019, 7, 79069-79084. [CrossRef]

71. Savold, R.; Dagher, N.; Frazier, P.; McCallam, D. Architecting cyber defense: A survey of the leading cyber reference architectures and frameworks. In Proceedings of the 2017 IEEE 4th International Conference on Cyber Security and Cloud Computing (CSCloud), New York, NY, USA, 26-28 June 2017; IEEE: Piscataway, NJ, USA, 2017; pp. 127-138.

72. de Jong, P.; van der Werf, J.M.E.; van Steenbergen, M.; Bex, F.; Brinkhuis, M. Evaluating design rationale in architecture. In Proceedings of the 2019 IEEE International Conference on Software Architecture Companion (ICSA-C), Hamburg, Germany, 25-26 March 2019; IEEE: Piscataway, NJ, USA, 2019; pp. 145-152.

73. Shahbazian, A.; Lee, Y.K.; Le, D.; Brun, Y.; Medvidovic, N. Recovering architectural design decisions. In Proceedings of the 2018 IEEE International Conference on Software Architecture (ICSA), Seattle, WA, USA, 30 April-4 May 2018; IEEE: Piscataway, NJ, USA, 2018; pp. 95-9509.

74. Krusche, S.; Bruegge, B. CSEPM-a continuous software engineering process metamodel. In Proceedings of the 2017 IEEE/ACM 3rd International Workshop on Rapid Continuous Software Engineering (RCoSE), Buenos Aires, Argentina, 22-23 May 2017; IEEE: Piscataway, NJ, USA, 2017; pp. 2-8.

75. Arcelli, D. Exploiting queuing networks to model and assess the performance of self-adaptive software systems: A survey. Procedia Comput. Sci. 2020, 170, 498-505. [CrossRef]

76. Palensky, P.; van der Meer, A.A.; Lopez, C.D.; Joseph, A.; Pan, K. Cosimulation of intelligent power systems: Fundamentals, software architecture, numerics, and coupling. IEEE Ind. Electron. Mag. 2017, 11, 34-50. [CrossRef]

77. Szmuc, W.; Szmuc, T. Towards Embedded Systems Formal Verification Translation from SysML into Petri Nets. In Proceedings of the 2018 25th International Conference" Mixed Design of Integrated Circuits and System"(MIXDES), Gdynia, Poland, 21-23 June 2018; IEEE: Piscataway, NJ, USA, 2018; pp. 420-423.

78. Coulin, T.; Detante, M.; Mouchère, W.; Petrillo, F. Software Architecture Metrics: A literature review. arXiv 2019, arXiv:1901.09050.

79. Soares, M.A.C.; Parreiras, F.S. A literature review on question answering techniques, paradigms and systems. J. King Saud Univ.-Comput. Inf. Sci. 2020, 32, 635-646.

80. Düllmann, T.F.; Heinrich, R.; van Hoorn, A.; Pitakrat, T.; Walter, J.; Willnecker, F. CASPA: A platform for comparability of architecture-based software performance engineering approaches. In Proceedings of the 2017 IEEE International Conference on Software Architecture Workshops (ICSAW), Gothenburg, Sweden, 5-7 April 2017; IEEE: Piscataway, NJ, USA, 2017 ; pp. $294-297$. 
81. Walter, J.; Stier, C.; Koziolek, H.; Kounev, S. An expandable extraction framework for architectural performance models. In Proceedings of the 8th ACM/SPEC on International Conference on Performance Engineering Companion, L'Aquila, Italy, 22-26 April 2017; pp. 165-170.

82. Singh, H. Secure SoftwareArchitecture and Design: Security Evaluation for Hybrid Approach. INROADS Int. J. Jaipur Natl. Univ. 2019, 8, 82-88.

83. Sujay, V.; Reddy, M.B. Advanced Architecture-Centric Software Maintenance. i-Manager's J. Softw. Eng. 2017, 12, 1.

84. Hassan, A.; Oussalah, M.C. Evolution Styles: Multi-View/Multi-Level Model for Software Architecture Evolution. JSW 2018, 13, 146-154. [CrossRef]

85. Dobrica, L.; Niemela, E. A survey on software architecture analysis methods. IEEE Trans. Softw. Eng. 2002, 28, 638-653. [CrossRef]

86. Plauth, M.; Feinbube, L.; Polze, A. A performance evaluation of lightweight approaches to virtualization. Cloud Comput. 2017, 2017,14 .

87. Li, Z.; Zheng, J. Toward industry friendly software architecture evaluation. In Proceedings of the European Conference on Software Architecture, Montpellier, France, 1-5 July 2013; Springer: Berlin/Heidelberg, Germany, 2013; pp. 328-331.

88. Abrahão, S.; Insfran, E. Evaluating software architecture evaluation methods: An internal replication. In Proceedings of the 21st International Conference on Evaluation and Assessment in Software Engineering, Karlskrona, Sweden, 15-16 June 2017; pp. 144-153.

89. Zalewski, A.; Kijas, S. Beyond ATAM: Early architecture evaluation method for large-scale distributed systems. J. Syst. Softw. 2013, 86, 683-697. [CrossRef]

90. Alsaqaf, W.; Daneva, M.; Wieringa, R. Quality requirements in large-scale distributed agile projects—A systematic literature review. In Proceedings of the International Working Conference on Requirements Engineering: Foundation for Software Quality, Essen, Germany, 27 February-2 March 2017; Springer: Berlin/Heidelberg, Germany, 2017; pp. 219-234.

91. Bass, L.; Nord, R.L. Understanding the context of architecture evaluation methods. In Proceedings of the 2012 Joint Working IEEE/IFIP Conference on Software Architecture and European Conference on Software Architecture, Helsinki, Finland, 20-24 August 2012; IEEE: Piscataway, NJ, USA, 2012; pp. 277-281.

92. Kasauli, R.; Knauss, E.; Horkoff, J.; Liebel, G.; Neto, F.G.d. Requirements engineering challenges and practices in large-scale agile system development. J. Syst. Softw. 2021, 172, 110851. [CrossRef]

93. Zhang, D.; Yu, F.R.; Yang, R. A machine learning approach for software-defined vehicular ad hoc networks with trust management. In Proceedings of the 2018 IEEE Global Communications Conference (GLOBECOM), Abu Dhabi, United Arab Emirates, 9-13 December 2018; IEEE: Piscataway, NJ, USA, 2018; pp. 1-6.

94. Cruz-Benito, J.; Garcia-Penalvo, F.J.; Theron, R. Analyzing the software architectures supporting HCI/HMI processes through a systematic review of the literature. Telemat. Inform. 2019, 38, 118-132. [CrossRef]

95. Poularakis, K.; Qin, Q.; Nahum, E.M.; Rio, M.; Tassiulas, L. Flexible SDN control in tactical ad hoc networks. Ad Hoc Netw. 2019, 85, 71-80. [CrossRef]

96. Li, X.-Y.; Liu, Y.; Lin, Y.-H.; Xiao, L.-H.; Zio, E.; Kang, R. A generalized petri net-based modeling framework for service reliability evaluation and management of cloud data centers. Reliab. Eng. Syst. Saf. 2021, 207, 107381. [CrossRef]

97. Varshosaz, M.; Beohar, H.; Mousavi, M.R. Basic behavioral models for software product lines: Revisited. Sci. Comput. Program. 2018, 168, 171-185. [CrossRef]

98. Ozkaya, M. Do the informal \& formal software modeling notations satisfy practitioners for software architecture modeling? Inf. Softw. Technol. 2018, 95, 15-33.

99. Bhat, M.; Shumaiev, K.; Hohenstein, U.; Biesdorf, A.; Matthes, F. The evolution of architectural decision making as a key focus area of software architecture research: A semi-systematic literature study. In Proceedings of the 2020 IEEE International Conference on Software Architecture (ICSA), Salvador, Brazil, 16-20 March 2020; IEEE: Piscataway, NJ, USA, 2020; pp. 69-80.

100. Seifermann, S.; Heinrich, R.; Reussner, R. Data-driven software architecture for analyzing confidentiality. In Proceedings of the 2019 IEEE International Conference on Software Architecture (ICSA), Hamburg, Germany, 25-29 March 2019; IEEE: Piscataway, NJ, USA, 2019; pp. 1-10.

101. Landauer, C.; Bellman, K.L. An architecture for self-awareness experiments. In Proceedings of the 2017 IEEE International Conference on Autonomic Computing (ICAC), Columbus, OH, USA, 17-21 July 2017; IEEE: Piscataway, NJ, USA, 2017 ; pp. $255-262$.

102. Ferraiuolo, A.; Xu, R.; Zhang, D.; Myers, A.C.; Suh, G.E. Verification of a practical hardware security architecture through static information flow analysis. In Proceedings of the Twenty-Second International Conference on Architectural Support for Programming Languages and Operating Systems, Xi'an, China, 1-8 April 2017; pp. 555-568.

103. van Engelenburg, S.; Janssen, M.; Klievink, B. Design of a software architecture supporting business-to-government information sharing to improve public safety and security. J. Intell. Inf. Syst. 2019, 52, 595-618. [CrossRef]

104. Bánáti, A.; Kail, E.; Karóczkai, K.; Kozlovszky, M. Authentication and authorization orchestrator for microservice-based software architectures. In Proceedings of the 2018 41st International Convention on Information and Communication Technology, Electronics and Microelectronics (MIPRO), Opatija, Croatia, 21-25 May 2018; IEEE: Piscataway, NJ, USA, 2018 ; pp. 1180-1184.

105. Tuma, K.; Scandariato, R.; Balliu, M. Flaws in flows: Unveiling design flaws via information flow analysis. In Proceedings of the 2019 IEEE International Conference on Software Architecture (ICSA), Hamburg, Germany, 25-29 March 2019; IEEE: Piscataway, NJ, USA, 2019; pp. 191-200. 
106. Santos, J.C.; Tarrit, K.; Mirakhorli, M. A catalog of security architecture weaknesses. In Proceedings of the 2017 IEEE International Conference on Software Architecture Workshops (ICSAW), Gothenburg, Sweden, 5-7 April 2017; IEEE: Piscataway, NJ, USA, 2017; pp. 220-223.

107. Ouma, W.Z.; Pogacar, K.; Grotewold, E. Topological and statistical analyses of gene regulatory networks reveal unifying yet quantitatively different emergent properties. PLoS Comput. Biol. 2018, 14, e1006098. [CrossRef] [PubMed]

108. Dissanayake, N.; Jayatilaka, A.; Zahedi, M.; Babar, M.A. Software security patch management-A systematic literature review of challenges, approaches, tools and practices. Inf. Softw. Technol. 2021, 144, 106771. [CrossRef]

109. De Vita, F.; Bruneo, D.; Das, S.K. On the use of a full stack hardware/software infrastructure for sensor data fusion and fault prediction in industry 4.0. Pattern Recognit. Lett. 2020, 138, 30-37. [CrossRef] 